\title{
Perfil metabólico de vacas mestiças leiteiras com baixo escore de condição corporal no periparto ${ }^{1}$
}

\author{
Raphael S.B.R. Oliveira ${ }^{2}$, Ana R.F. Moura², Mariana F.S. Pádua², Isadora M. Barbon², \\ Meire E.M. Silva ${ }^{3}$, Ricarda M. Santos ${ }^{2}$, Antonio V. Mundim² e João P.E. Saut ${ }^{2}$
}

\begin{abstract}
Oliveira R.S.B.R., Moura A.R.F., Pádua M.F.S., Barbon I.M., Silva M.E.M., Santos R.M., Mundim A.V. \& Saut J.P.E. 2014. [Metabolic profile in crossbred dairy cows with low body condition score in the peripartum period.] Perfil metabólico de vacas mestiças leiteiras com baixo escore de condição corporal no periparto. Pesquisa Veterinária Brasileira 34(4):362-368. Faculdade de Medicina Veterinária, Universidade Federal de Uberlândia, Uberlândia, MG 38400-902, Brazil. E-mail: jpsaut@famev.ufu.br

The aim of this study was to evaluate the metabolic profile of protein, energy and enzyme in crossbred dairy cows with low body condition score (BCS) in the peripartum period. Blood samples were collected from 36 animals with $2.6 \pm 0.5 \mathrm{BCS}$, eutocia, physiological postpartum and without any treatment, on following days: one week before calving, calving and 7, 14, 21, 28 and 43 days in milk (DIM). It was evaluated serum total protein, albumin and globulins for protein profile; AST, ALT, GGT and alkaline phosphatase for mineral profile; nonesterified fatty acids (NEFA), $\beta$-hydroxybutyrate (BHBA), triglycerides, cholesterol and lipoproteins (VLDL, HDL and LDL) for energy profile. Crossbred dairy cows had hypoproteinemia, hypoalbuminemia, hypocholesterolemia and increased that both enzymes AST and GGT at the precalving. There were lipolysis and hypoglobulinemia at parturition. It was concluded that crossbred dairy cows with low BCS have negative energy balance, hypoproteinemia with hypoalbuminemia and hepatic injury in the peripartum. This condition is restored at $30 \mathrm{DIM}$, but there is no recovery of the body condition by the end of puerperium.
\end{abstract}

INDEX TERMS: Dairy cattle, biochemistry profile, metabolic profile, postpartum, calving, eutocia.

RESUMO.- Objetivou-se avaliar o perfil metabólico energético, proteico e enzimático de vacas mestiças leiteiras com baixo escore de condição corporal (ECC) no periparto. Foram colhidas amostras sanguíneas uma semana antes do parto, no dia do parto, e aos sete, 14, 21, 28 e 43 dias pós-parto (DPP) de 36 animais, com média de ECC de 2,6 $\pm 0,5$, com eutocia e pós-parto fisiológico e sem tratamentos nesta fase. Analisaram-se as concentrações séricas de proteínas totais, albumina e globulinas para o perfil protéico; AST, ALT, GGT e fosfatase alcalina para o perfil enzimático; ácidos graxos não-esterificados (NEFA), $\beta$-hidroxibutirato

\footnotetext{
${ }^{1}$ Recebido em 30 de outubro de 2013.

Aceito para publicação em 24 de fevereiro de 2014.

${ }^{2}$ Faculdade de Medicina Veterinária, Universidade Federal de Uberlândia (UFU), Av. Pará 1720, Bloco 2T, Campus Umuarama, Bairro Umuarama, Uberlândia, MG 38400-902, Brasil. E-mail: jpsaut@famev.ufu.br

${ }^{3}$ Hospital Veterinário, UFU, Uberlândia, Av. Mato Grosso 3289, Bloco 2S, Campus Umuarama, Uberlândia, MG 38405-314.
}

(BHBA), triglicerídeos, colesterol e lipoproteínas (VLDL, HDL e LDL) para o perfil energético. As vacas apresentaram no pré-parto hipoproteinemia, hipoalbuminemia, hipocolesterolemia e aumento das enzimas GGT e AST. No dia do parto houve lipólise e hipoglobulinemia. Concluiu-se que vacas mestiças leiteiras com baixo ECC apresentam balanço energético negativo, hipoproteinemia com hipoalbuminemia e lesão hepática no periparto, com restabelecimento aos 30 DPP, mas não recuperam sua condição corporal até o final do puerpério.

TERMOS DE INDEXAÇÃO: Bovinos leiteiros, perfil bioquímico, perfil metabólico, pós-parto, parição, eutocia.

\section{INTRODUÇÃO}

A utilização do perfil metabólico ganhou importância nestes últimos anos, principalmente, relacionado às doenças no periparto de bovinos leiteiros, com auxílio no diagnóstico, prognóstico, prevenção (Duffield et al. 2009, Du- 
buc et al. 2010, Chapinal et al. 2011, Roberts et al. 2012) e na predição do desempenho reprodutivo (Chapinal et al. 2012, Dubuc et al. 2012). Além de permitir o diagnóstico pré-sintomático de alterações metabólicas e a avaliação da condição nutricional do rebanho (Payne et al. 1970).

0 período entre o final da gestação e início de lactação é o momento de maior alteração no metabolismo de vacas leiteiras, constituindo um desafio para o organismo animal, com cerca de $75 \%$ das doenças ocorrendo no primeiro mês pós-parto (Leblanc et al. 2006). Enfermidades como a metrite, retenção de placenta e deslocamento de abomaso estão relacionadas com balanço energético negativo e redução de $30 \%$ na ingestão de matéria seca no periparto (Chapinal et al. 2011).

O balanço energético negativo desencadeia a lipólise que pode provocar lesões hepáticas devido à infiltração gordurosa. No entanto, o fígado é um órgão pouco acessível aos métodos clássicos da semiologia e as manifestações das enfermidades hepáticas são pouco evidentes, sendo os exames laboratoriais fundamentais ao diagnóstico (Souza et al. 2004, Leblanc et al. 2006).

Em vacas Holandesas estas variações da bioquímica sérica têm sido bem exploradas, tanto com dados nacionais como internacionais, porém em vacas mestiças leiteiras, criadas nas condições de manejo e clima brasileiros, ainda percebe-se uma carência de informações técnicas e menos ainda nos animais com baixa condição corporal. Ao se considerar que estes sistemas de produção tornam-se cada vez mais eficientes, o risco de transtornos metabólicos aumenta, favorecendo o desequilíbrio entre a ingestão de nutrientes no organismo e a sua capacidade para metabolizá-los.

Devido a grande importância dos exames laboratoriais como ferramentas prognósticas e diagnósticas nesta fase e a maior parte do rebanho leiteiro brasileiro ser constituído de animais mestiços (Facó et al. 2002), objetivou-se avaliar o perfil metabólico energético, proteico e enzimático de vacas mestiças leiteiras no periparto com baixo escore de condição corporal.

\section{MATERIAL E MÉTODOS}

Local, instalação, alimentação e animais: aprovado pela Comissão de Ética na Utilização de Animais (CEUA) da Universidade Federal de Uberlândia (UFU), sob o processo número 133/10, este estudo foi conduzido na Fazenda Experimental do Glória, UFU, município de Uberlândia, sudoeste do Estado de Minas Gerais, Brasil. 0 clima local é classificado como Aw (Köppen 1948), com temperatura média anual de $22,3^{\circ} \mathrm{C}$, umidade relativa do ar em torno de $71 \% \mathrm{e}$ precipitação pluviométrica de $1500 \mathrm{~mm}$ anuais.

Durante o período das águas, os animais foram mantidos sob o sistema de pastejo rotacionado de Brachiaria decumbens, já durante o período de seca, foram alimentados com silagem de sorgo. Independentemente do período climático, suplementou-se durante as duas ordenhas diárias, com $1 \mathrm{~kg}$ de concentrado com $24 \%$ de proteína bruta para cada $3 \mathrm{~kg}$ de leite produzido.

Foram utilizadas 36 vacas leiteiras mestiças, Holandês x Gir, com composição genética variando de $1 / 2$ a $7 / 8$ com parição entre junho e dezembro de 2009. As vacas apresentavam escore de condição corporal (ECC) no pré-parto igual a 2,6 $\pm 0,5$ e média de produção leiteira de 20,8 litros/vaca/dia nos primeiros 90 dias pós-parto (DPP). Todos os animais com eutocia, puerpério fisio- lógico, sem alterações no exame clínico proposto (Feitosa 2008) e sem tratamento no período avaliado.

No pré-parto as vacas foram separadas individualmente até o momento do parto e depois transferidas para o lote lactação. Os animais eram vacinados anualmente contra febre aftosa, raiva, clostridioses e leptospirose e realizado exame periódico para tuberculose, brucelose e leptospirose.

Exame clínico e coleta das amostras de sangue. 0 exame físico geral foi procedido de acordo com o recomendado por Feitosa (2008), no qual se avaliou: temperatura retal; frequência cardíaca; frequência respiratória, frequência ruminal e escore de condição corporal (ECC), classificado de 1 a 5, com subunidades de 0,25 (Edmonson et al. 1989). Para avaliar a involução uterina e presença de infecções uterinas, realizou-se a ultrassonografia transretal com aparelho DP 2200vet (Mindray ${ }^{\circledR}$ ) e transdutor eletrônico 5-10 MHz, exame de vaginoscopia e avaliação de secreção vaginal (Williams et al. 2005). As coletas de sangue e exame clínico foram sempre realizadas após a ordenha na mão e nos seguintes momentos: sete dias antes do parto (d-7), parto (d0) e sete (d7), 14 (d14), 21 (d21), 28 (d28) e 43 (d43) DPP. As coletas de sangue foram feitas por venopunção da veia caudal mediana, com sistema a vácuo, e acondicionadas em tubo seco próprio para realização das dosagens bioquímicas, refrigeradas e encaminhadas ao Laboratório de Análises Clínicas do Hospital Veterinário - UFU.

Processamento das amostras e análises bioquímicas: No laboratório, as amostras foram centrifugadas a $720 \mathrm{~g}$, durante 8 minutos, em centrífuga Excelsa Baby (centrífuga marca FANEM, modelo 206), e o soro separado em microtubos tipo eppendorf, e armazenado a menos $20^{\circ} \mathrm{C}$ até o momento das análises, no máximo cinco dias após a coleta.

As análises bioquímicas séricas foram realizadas em analisador automático multicanal ChemWell (Awareness Technology Inc. ${ }^{\circledR}$ ), a $37^{\circ} \mathrm{C}$, previamente calibrado (Calibra $\mathrm{H}$ ) e aferido com soro controle (Qualitrol 1). Os parâmetros analisados e os métodos utilizados para a determinação do perfil protéico foram à concentração sérica da proteína total (biureto), de albumina (verde bromocresol) e concentração de globulina (proteína total menos albumina) determinada por Coles (1984). As enzimas determinadas com respectiva metodologia foram: alanina aminotransferase (ALT) e aspartato aminotransferase (AST) pelo método cinético UV-IFCC; gama glutamiltransferase (GGT), método Szasz modificado; fosfatase alcalina (FA) - método cinético optimizado - Bowers e McComb modificado.

No perfil energético foram determinadas as concentrações séricas de $\beta$-hidroxibutirato (BHBA) pelo método cinético enzimático (Randox Laboratories Ltd), ácidos graxos não-estereficados (NEFA) pelo método colorimétrico (Randox Laboratories Ltd), triglicerídeos, colesterol pelo método enzimático Trinder, lipoproteínas de alta densidade (HDL) pelo método colorimétrico de ponto final após precipitação seletiva das lipoproteínas de baixa densidade. Utilizando a equação de Friedewald et al. (1972) foram calculadas as concentrações das lipoproteínas de muita baixa densidade (VLDL) triglicerídeos/5 e lipoproteínas de baixa densidade (LDL) colesterol total-(HDL+VLDL).

Análise estatística. Para análise estatística, utilizou-se o programa Minitab Release 15 (Minitab Inc. Pensylvania, USA), sendo os dados apresentados em média aritmética e desvio-padrão. As variáveis, inicialmente, foram submetidas ao Teste de Kolmogorov-Smirnov para verificar se os dados apresentavam ou não distribuição paramétrica. As variáveis com distribuição paramétrica (proteínas totais, globulina, albumina, BHBA, HDL, VLDL, LDL, triglicerídeos, ALT, AST, GGT, FA e produção leiteira) foram submetidas à análise de variância (ANOVA paramétrica) e pós-teste 
de Tukey's. As variáveis com distribuição não-paramétrica (NEFA, colesterol e ECC) foram analisadas pelo teste de Kruskall-Wallis (ANOVA não-paramétrica) e pós-teste de Comparação Múltipla de Dunn's. Todos os testes com nível de significância de 95\% (p s $0,05)$. A interpretação da correlação linear de Pearson foi feita de acordo com Callegari-Jacques (2003).

\section{RESULTADOS E DISCUSSÃO}

Em relação ao perfil sérico proteico, verificou-se que as concentrações das proteínas totais e albumina já se apresentavam baixas no pré-parto, provavelmente, influenciada pela deficiência nutricional de proteínas (Contreras 2000). Após o parto permaneceram abaixo dos valores de referência (Kaneko et al. 2008) e de vacas Girolando, entre 17 e 78 DPP $(7,38 \pm 0,07 \mathrm{~g} / \mathrm{dL})$, e vacas Holandesas no puerpério recente $(7,56 \pm 0,66 \mathrm{~g} / \mathrm{dL})$ e tardio $(8,84 \pm 0,87 \mathrm{~g} / \mathrm{dL})$ criadas no Brasil (Souza et al. 2008, Zambrano \& Marques Júnior 2009). Apesar dos valores baixos, houve um aumento significante destes metabólitos no decorrer do puerpério (Quadro 1).

Quadro 1. Perfil sérico protéico e escore de condição corporal (ECC) de vacas mestiças leiteiras com baixo escore de condição corporal no periparto

\begin{tabular}{|c|c|c|c|c|}
\hline $\begin{array}{l}\text { Dias pós- } \\
\text {-parto }\end{array}$ & $\begin{array}{l}\text { Proteínas totais } \\
(\mathrm{g} / \mathrm{dL})\end{array}$ & $\begin{array}{c}\text { Globulina } \\
\text { (g/dL) }\end{array}$ & $\begin{array}{l}\text { Albumina } \\
(\mathrm{g} / \mathrm{dL})\end{array}$ & ECC \\
\hline-7 & $5,85 \pm 0,56^{a b}$ & $3,03 \pm 0,61^{a b}$ & $2,82 \pm 0,29^{a b}$ & $2,7 \pm 0,5^{a}$ \\
\hline Parto & $5,74 \pm 0,61^{a}$ & $2,87 \pm 0,54^{a}$ & $2,88 \pm 0,33^{a b}$ & $2,6 \pm 0,5^{a}$ \\
\hline 7 & $6,33 \pm 0,80 b c$ & $3,16 \pm 0,81 \mathrm{ab}$ & $3,17 \pm 0,36^{a c}$ & $2,5 \pm 0,5^{a}$ \\
\hline 14 & $6,19 \pm 0,72^{a b c}$ & $3,84 \pm 0,66^{c}$ & $2,34 \pm 0,34^{d}$ & $2,6 \pm 0,5^{a}$ \\
\hline 21 & $6,18 \pm 0,688^{a b c}$ & $3,49 \pm 0,80 \mathrm{bc}$ & $2,69 \pm 0,66^{b}$ & $2,6 \pm 0,5^{a}$ \\
\hline 28 & $6,53 \pm 0,59 \mathrm{~cd}$ & $3,29 \pm 0,71^{a b}$ & $3,22 \pm 0,60^{c}$ & $2,6 \pm 0,5^{a}$ \\
\hline 43 & $6,95 \pm 0,61^{d}$ & $3,93 \pm 0,83^{c}$ & $3,12 \pm 0,22 \mathrm{ac}$ & $2,7 \pm 0,5^{a}$ \\
\hline Referência $^{a}$ & $6,74-7,46$ & $3,00-3,48$ & $3,03-3,55$ & - \\
\hline
\end{tabular}

$\bar{a}$ Kaneko et al. (2008). Letras diferentes na coluna diferem estatisticamente $(\mathrm{p}<0,05)$.

Em relação à concentração de globulinas, esta esteve inferior apenas no dia do parto, semelhante ao encontrado por Feitosa \& Birgel (2000). Esta queda de globulinas, observada também nas proteínas totais, é devido à transferência de globulinas para a síntese de colostro na glândula mamária, como parte de um processo fisiológico e que se estende nos dias seguintes ao parto (Feitosa \& Birgel 2000, Nath et al. 2005, Saut 2008).

0 aumento das proteínas séricas foi mais lento, o que pode ser explicado pelas concentrações de albumina (Quadro 1), que até os 28 DPP estavam abaixo ou no limite inferior dos valores de referência (Kaneko et al. 2008). Zambrano \& Marques Júnior (2009) verificaram em vacas Girolando, com ECC adequado na parição, uma queda semelhante na albumina durante o puerpério, com valores de $31,12 \pm 2,06 \mathrm{~g} / \mathrm{L}, 27,4 \pm 3,61 \mathrm{~g} / \mathrm{L}$ e $29,29 \pm 2,49 \mathrm{~g} / \mathrm{L}$, respectivamente, no pré-parto, entre 17-78 e 110-153 DPP. Os autores sugeriram que esta queda poderia estar relacionada com a quantidade de proteína na dieta, aumento na demanda de aminoácidos para a síntese de proteínas lácteas ou redução da capacidade de síntese no fígado devido ao acúmulo de gordura.

Souza (2005) cita que esta queda de albumina pode ser atribuída aos distúrbios metabólicos e hepáticos no periparto das vacas leiteiras, que levaria à diminuição do aporte de energia e nutrientes para a síntese hepática de proteínas, ou mesmo causar lesões hepáticas que diminuíssem ou inibissem a síntese proteica. Birgel Junior et al. (2003) descrevem no pós-parto de vacas Holandesas um quadro de hipoalbuminemia e relação albumina-globulina próxima do limite de quadros caracterizados por insuficiência hepática.

Outro fator que poderia explicar a queda de albumina seria a sua resposta de fase aguda frente a processos inflamatórios, como nos casos de retenção de placenta e endometrite (Souza 2005, Saut 2008), mas que pode ser descartado, pois os animais foram examinados em relação à presença de infecções uterinas, mastite, afecções podais, respiratórias e outras doenças no periparto.

A avaliação da função hepática (Quadro 2) demonstrou um quadro de lesão hepática leve no periparto, demonstrado pelo aumento das enzimas GGT e AST. A concentração sérica de GGT esteve aumentada de uma semana antes até a parição, de acordo com os valores de referência de Kaneko et al. (2008) e dados nacionais da raça Girolando $(12,5 \pm 0,39 \mathrm{U} / \mathrm{L})$, Gir $(11,8 \pm 0,55 \mathrm{U} / \mathrm{L})$ e mais precisamente no puerpério recente até $10 \mathrm{DPP}(15,08 \pm 9,59 \mathrm{U} / \mathrm{L})$ e puerpério tardio entre 30 e 45 DPP $(12,64 \pm 4,56 \mathrm{U} / \mathrm{L})$ em vacas Holandesas (Souza 1997, Souza et al. 2008).

Quadro 2. Perfil sérico enzimático de vacas mestiças leiteiras com baixo escore de condição corporal no periparto

\begin{tabular}{ccccc}
\hline $\begin{array}{c}\text { Dias pós- } \\
\text {-parto }\end{array}$ & ALT (U/L) & AST (U/L) & GGT (U/L) & FA (U/L) \\
\hline-7 & $16,89 \pm 4,74^{\mathrm{ab}}$ & $55,67 \pm 12,77^{\mathrm{a}}$ & $17,96 \pm 6,10^{\mathrm{abc}}$ & $50,26 \pm 17,01^{\mathrm{ab}}$ \\
Parto & $20,02 \pm 5,07^{\mathrm{ab}}$ & $69,14 \pm 13,63^{\mathrm{ab}}$ & $20,81 \pm 6,75^{\mathrm{a}}$ & $56,54 \pm 16,72^{\mathrm{a}}$ \\
7 & $16,48 \pm 4,52^{\mathrm{a}}$ & $72,90 \pm 20,22^{\mathrm{b}}$ & $16,10 \pm 5,74^{\mathrm{abc}}$ & $35,25 \pm 10,47^{\mathrm{c}}$ \\
14 & $20,97 \pm 6,87^{\mathrm{ab}}$ & $78,11 \pm 23,86^{\mathrm{b}}$ & $16,16 \pm 5,79^{\mathrm{bc}}$ & $49,70 \pm 24,84^{\mathrm{ab}}$ \\
21 & $20,11 \pm 8,01^{\mathrm{ab}}$ & $74,14 \pm 16,19^{\mathrm{b}}$ & $19,67 \pm 8,06^{\mathrm{ab}}$ & $41,38 \pm 13,44^{\mathrm{bc}}$ \\
28 & $21,56 \pm 7,4^{2 \mathrm{~b}}$ & $59,39 \pm 15,69^{\mathrm{a}}$ & $15,06 \pm 5,07^{\mathrm{c}}$ & $38,77 \pm 11,72^{\mathrm{bc}}$ \\
43 & $27,70 \pm 8,64^{\mathrm{c}}$ & $68,52 \pm 15,29^{\mathrm{ab}}$ & $18,41 \pm 6,64^{\mathrm{ac}}$ & $43,45 \pm 11,05^{\mathrm{bc}}$ \\
Referência $^{\mathrm{a}}$ & $11-40$ & $78-132$ & $6,1-17,4$ & $0-488$
\end{tabular}

${ }^{a}$ Kaneko et al. (2008). Letras diferentes na coluna diferem estatisticamente $(p<0,05)$. ALT (alanina aminotransferase), AST (aspartato aminotransferase), GGT (gama-glutamil transferase) e FA (fosfatase alcalina).

A enzima AST não esteve aumentada nesta fase (valores entre $55,67 \pm 12,77$ e 78,11 $\pm 23,86 \mathrm{U} / \mathrm{L}$ ) quando comparada com Kaneko et al. (2008); porém ao confrontar com

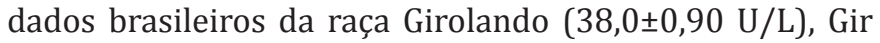
$(35,3 \pm 0,99 \mathrm{U} / \mathrm{L})$ e vacas no puerpério recente até $10 \mathrm{DPP}$ $(47,85 \pm 11,8 \mathrm{U} / \mathrm{L})$ e tardio entre 30 e 45 DPP $(38,94 \pm 8,2$ U/L) da raça Holandês (Souza 1997, Souza et al. 2008), os valores séricos de AST encontraram-se aumentados.

$\mathrm{O}$ aumento de AST, no dia do parto, pode ser reflexo do esforço muscular que ocorre durante a parição, o que provocaria a lise de fibras musculares e aumentaria as concentrações séricas na fase inicial do puerpério, porém, em virtude da meia-vida desta enzima ser curta (Souza et al. 2008), estes valores deveriam diminuir; no entanto aumentaram até os 21DPP, sugerindo a presença de lesão hepática.

Ao considerar o valor de AST acima de $100 \mathrm{U} / \mathrm{L}$, como sugestivo de lesão hepática devido à esteatose, como citado 
por González et al. (2009), os dados individuais das vacas mestiças demonstraram que $6,5 \%, 17,1 \%$ e $5,6 \%$ apresentaram lesões hepáticas aos 7, 14 e 21DPP, respectivamente.

As concentrações séricas de ALT e FA permaneceram dentro da normalidade (Kaneko et al. 2008), apesar de haver variação significativa das médias (Quadro 2). Tainturier et al. (1984) descreveram uma atividade diminuída da ALT no início da lactação e, de acordo com González \& Silva (2006) a FA é considerada de pouca importância em doenças hepáticas nos ruminantes, devido à sua grande amplitude de variação fisiológica.

0 perfil metabólico energético demonstrou lipólise no dia do parto com valores do NEFA de $0,86 \pm 0,44 \mathrm{mmol} / \mathrm{L}$ (Fig.1A). Conforme afirma Oetzel (2008), valores de NEFA maiores que $0,4 \mathrm{mmol} / \mathrm{L}$ são indicativos de lipomobilização. Os valores de NEFA retornaram apenas na segunda semana ao recomendado para o puerpério recente, em vacas Holandesas, entre 0,26 e 0,52mmol/L (Pogliani \& Birgel Júnior 2007).

Os valores de NEFA, nas vacas mestiças leiteiras com baixo ECC apresentaram valores semelhantes aos encontrados por González et al. (2009), em vacas Holandesas de alta produção $(0,536 \mathrm{mmol} / \mathrm{L})$, com média de 40 litros no primeiro mês de lactação, bem diferente da produção média das vacas mestiças leiteiras avaliadas neste estudo (Fig.2).

Os valores séricos de BHBA (Fig.1B) aumentaram significativamente até o $21^{\circ} \mathrm{DPP}$, porém se mantiveram dentro dos valores de referência entre 0,579 e 1,066mmol/L (Pogliani \& Birgel Júnior 2007), como parte da resposta metabólica ao aumento na exigência energética para produção leiteira (Vásquez-Añon et al. 1994, Contreras 2000, Wittwer 2000). Este aumento de BHBA se deve à mobilização de triglicerídeos do tecido adiposo, demonstrado pela alta concentração sérica de NEFA que é substrato para a cetogênese.

Apesar destas vacas não apresentarem metrite, obtiveram valores de NEFA superiores $(\geq 0,6 \mathrm{mmol} / \mathrm{L})$ aos considerado por Dubuc et al. (2010) como fator de risco para esta infecção uterina, na primeira semana pós-parto. Valores elevados de NEFA prejudicam a atividade de neutrófilos e saúde uterina (Hammon et al. 2006).

0 balanço energético negativo determinado pelas dosagens de NEFA e BHBA não foi acompanhado de queda significativa do ECC, além de apresentar fraca correlação com BHBA $(p=0,06)$ e NEFA $(p=-0,02)$. Apesar de ser um método fácil e confiável de estimar o estado nutricional de vacas leiteiras (Edmonson et al. 1989), nesta pesquisa, nas vacas leiteiras mestiças com baixo ECC no periparto, não houve relação do ECC com o metabolismo energético, como é descrito na literatura (Busato et al. 2002). Freitas Júnior et al. (2008) verificaram que vacas mestiças Holandês x Zebu, com baixo ECC no parto $(<3,25)$, mobilizam menor quantidade de reservas corporais comparadas com vacas com ECC $\geq 3,25$ e apresentam menor porcentagem de gordura no leite e produção leiteira corrigida para 3,5\%.

Ao contrário do BHBA, a concentração de triglicerídeos é menor durante o período de lactação, devido à maior demanda pela glândula mamária para a síntese de gordura láctea (Christie 1981, Costa 1991, Pogliani \& Birgel Junior 2007) e podem ser menores ainda se o quadro de esteatose hepática estiver associado (Van Den Top et al. 2005). Nas
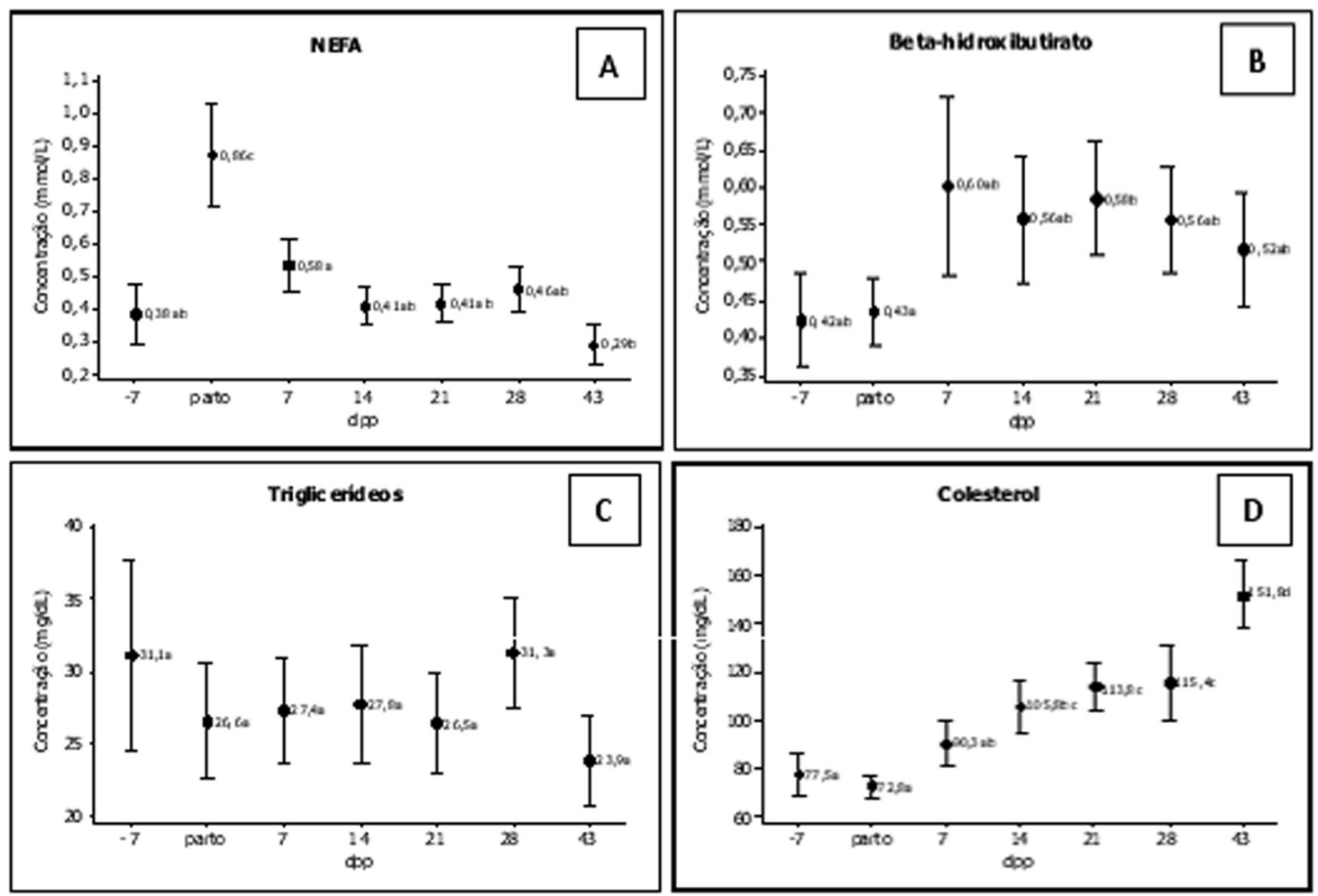

Fig.1. Perfil metabólico energético de vacas mestiças leiteiras com baixo escore de condição corporal no periparto. NEFA e colesterol (Teste Kruskall-Wallis, $p \leq 0,05$ ); $\beta$-hidroxibutirato e triglicerídeos (Teste de Tukey, $\mathrm{p} \leq 0,05)$. 


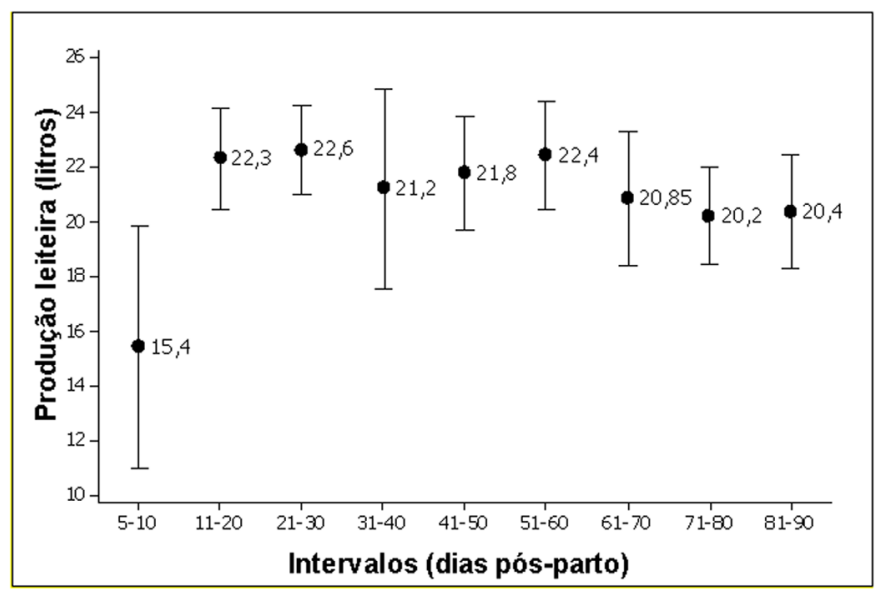

Fig.2. Produção leiteira de vacas mestiças nos primeiros 90 dias pós-parto.

Quadro 3. Concentração sérica de lipoproteínas de vacas mestiças leiteiras com baixo escore de condição corporal no periparto

\begin{tabular}{lccc}
\hline Dias & HDL $(\mathrm{mg} / \mathrm{dL})$ & VLDL(mg/dL) & LDL $(\mathrm{mg} / \mathrm{dL})$ \\
\hline-7 & $18,24 \pm 3,50^{\mathrm{a}}$ & $6,22 \pm 2,60^{\mathrm{a}}$ & $52,92 \pm 15,09^{\mathrm{ab}}$ \\
Parto & $20,73 \pm 6,64^{\mathrm{a}}$ & $5,33 \pm 2,72^{\mathrm{a}}$ & $46,72 \pm 13,24^{\mathrm{a}}$ \\
7 & $18,20 \pm 5,07^{\mathrm{a}}$ & $5,47 \pm 1,93^{\mathrm{a}}$ & $67,27 \pm 23,88^{\mathrm{abc}}$ \\
14 & $24,03 \pm 9,70^{\mathrm{ab}}$ & $5,56 \pm 2,33^{\mathrm{a}}$ & $76,23 \pm 29,63^{\mathrm{bc}}$ \\
21 & $30,52 \pm 9,51^{\mathrm{c}}$ & $5,30 \pm 2,08^{\mathrm{a}}$ & $77,95 \pm 24,73^{\mathrm{bc}}$ \\
28 & $31,19 \pm 10,1^{\mathrm{c}}$ & $6,26 \pm 2,19^{\mathrm{a}}$ & $79,73 \pm 44,42^{\mathrm{c}}$ \\
43 & $29,72 \pm 11,9^{\mathrm{bc}}$ & $4,77 \pm 1,78^{\mathrm{a}}$ & $119,55 \pm 35,55^{\mathrm{d}}$
\end{tabular}

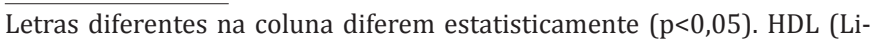
poproteína de alta densidade), VLDL (Lipoproteína de densidade muito baixa), LDL (Lipoproteína de baixa densidade).

vacas leiteiras mestiças não houve variação da concentração sérica de triglicerídeos no periparto e foram superiores aos valores de referência (Kaneko et al. 2008) e de vacas Girolando $(15,18 \pm 2,85 \mathrm{mg} / \mathrm{dL}$ ) entre 17 e 78 DPP (Zambrano \& Marques Júnior 2009).

A lipoproteína VLDL (Quadro 3) apresentou a mesma dinâmica dos triglicerídeos, sem alteração significativa no periparto, sendo que a presença desta lipoproteína é fundamental no transporte de triglicerídeos no plasma. Em bovinos, particularmente, a baixa capacidade de síntese hepática de VLDL predispõe a esteatose hepática (Hocquette \& Bauchart 1999, Kaneko et al. 2008).

Os valores encontrados de colesterol até o parto foram inferiores aos de referência $(80-120 \mathrm{mg} / \mathrm{dL})$, proposto por Kaneko et al. (2008) e de vacas Holandesas até a primeira semana pós-parto $(94,63-146,93 \mathrm{mg} / \mathrm{dL})$ (Pogliani 2006). Porém, estiveram dentro dos valores descritos por Souza \& Birgel Junior (2009), no puerpério recente $(31,0-109,9 \mathrm{mg} /$ dL) e puerpério tardio $(82,8-220,6 \mathrm{mg} / \mathrm{dL})$ e aumentaram significativamente no pós-parto (Fig.1D), fato também observado por Kappel et al. (1984), Costa (1991), Gueorguieva \& Gueorguiev (1997) e Souza (2005). A lipoproteína LDL apresentou a mesma dinâmica (Quadro 3), pois esta é a principal carreadora do colesterol (Bauchart 1993, González \& Silva 2006, Kaneko et al. 2008).

0 déficit de colesterol ocorre especialmente antes do início da lactação devido à mobilização de gordura, como forma de adaptação do organismo animal, devido à diminuição no consumo voluntário de matéria seca, crescimento fetal e preparação da glândula mamária para lactação (Ceballos et al. 2002), além disso, pode refletir dieta deficiente de nutrientes energéticos (González 2000).

A concentração sérica da HDL (Quadro 3) apresentou aumento semelhante ao colesterol no pós-parto, com correlação linear de $96,6 \%$ e tem como objetivo minimizar os efeitos deletérios do colesterol (González \& Silva 2006) e ser sintetizados em VLDL ou excretados via bile (Bauchart 1993). Esta lipoproteína encontra-se diminuída no pré-parto devido à exigência energética necessária para o crescimento do feto e preparação da glândula mamária (Ceballos et al. 2002). Apesar da HDL representar mais de $80 \%$ do total de lipoproteínas circulantes no plasma dos bovinos, o transporte dos triglicerídeos é realizado por lipoproteínas de baixa densidade, principalmente, as VLDL e quilomicrons (Hocquette \& Bauchart 1999).

Estes animais se recuperaram do balanço energético negativo no final do primeiro mês pós-parto, porém neste período apresentaram problemas no metabolismo hepático e energético e não recuperaram a condição corporal. Sugere-se que o quadro de hipoproteinemia, hipoalbuminemia, hipocolesterolemia e inadequada condição corporal presentes no pré-parto contribuíram para a extensão deste balanço energético negativo no puerpério. Por este motivo, reforça-se a importância de adequado manejo e dieta no pré-parto, tanto na parte proteica como energética, já que se verifica um aumento no uso destes animais em sistemas mais intensivos de produção leiteira no Brasil.

A queda de albumina no periparto é restabelecida, desde que o aporte de proteínas na dieta seja adequado e, caso isso não ocorra, essa diminuição pode persistir por dois ou três meses pós-parto (Contreras 2000). A nutrição com baixa qualidade proteica pode ser um fator importante a ser considerado nas pequenas e médias propriedades leiteiras e justificar a baixa concentração de proteína e albumina sérica (González \& Silva 2006, Kaneko et al. 2008), já que normalmente não há uma ingestão adequada de proteínas por estes animais, devido, principalmente, ao alto custo deste ingrediente na alimentação animal.

\section{CONCLUSÃO}

Concluiu-se que vacas mestiças leiteiras com baixo escore de condição corporal apresentam balanço energético negativo, hipoproteinemia com hipoalbuminemia e lesão hepática no periparto, com restabelecimento aos 30 dias pós-parto, porém antes da recuperação da condição corporal.

Agradecimentos.- Ao Conselho Nacional de Desenvolvimento Científico e Tecnológico (CNPq), à Fundação de Amparo à Pesquisa do Estado de Minas Gerais (Fapemig) e Universidade Federal de Uberlândia pelo auxílio financeiro e bolsa de mestrado. Aos funcionários da Fazenda Experimental do Glória da Universidade Federal de Uberlândia.

\section{REFERÊNCIAS}

Bauchart D. 1993. Lipid absorption and transport in ruminants. J. Dairy Sci. 76:3864-3881,

Birgel Junior E.H., Neves F.S., Salvatore L.C.A., Mirandola R.M., Távora J.P.F. \& Birgel E.H. 2003. Avaliação da influência da gestação e do puerpério 
sobre a função hepática de bovinos da raça Holandesa. Ars Vet. 19:172178.

Busato A., Faissler D., Kupfer U. \& Blum J.W. 2002. Body condition scores in dairy cows: associations with metabolic and endocrine changes in healthy dairy cows. J. Vet. Med. A 49:455-460.

Callegari-Jacques S.M. 2003. Bioestatística: princípios e aplicações. Artmed, Porto Alegre. 255p.

Ceballos A., Villa N.A., Bohórquez A., Quiceno J., Jaramillo M. \& Giraldo G. 2002. Análisis de los resultados de perfiles metabólicos en lecherías del tropico alto del eje cafetero colombiano. Revta Colombiana Cienc. Pecuarias 15:26-35.

Chapinal N., Carson M., Duffield T.F., Capel M., Godden S., Overton M., Santos J.E. \& Leblanc S.J. 2011. The association of serum metabolites with clinical disease during the transition period. J. Dairy Sci. 94:4897-4903.

Chapinal N., Carson M.E., Leblanc S.J., Leslie K.E., Godden S., Capel M., Santos J.E., Overton M.W. \& Duffield T.F. 2012. The association of serum metabolites in the transition period with milk production and early-lactation reproductive performance. J. Dairy Sci. 95:1301-1309.

Christie W.W. 1981. Lipid Metabolism in Ruminants Animals. Pergamon Press, Oxford. 452p.

Coles E.H. 1984. Patologia Clínica Veterinária. 3aㅗ ed. Manole, São Paulo. 566p.

Contreras P.A. 2000. Indicadores do metabolismo protéico utilizados nos perfis metabólicos de rebanhos, p.23-30. In: González F.H.D., Barcellos J., Patiño H.O. \& Ribeiro L.A. (Eds), Perfil Nutricional em Ruminantes: seu uso em nutrição e doenças nutricionais. Editora da UFRGS, Porto Alegre.

Costa S.E. 1991. Perfil lipídico de vacas Holandesas, variedades HPB, em diferentes fases de gestação. Dissertação de Mestrado em Clínica Veterinária, Faculdade de Medicina Veterinária e Zootecnia, Universidade de São Paulo, São Paulo, SP. 57p.

Dubuc J., Duffield T.F., Leslie K.E., Walton J.S. \& Leblanc S.J. 2010. Risk factors for postpartum uterine diseases in dairy cows. J. Dairy Sci. 93:57645771.

Dubuc J., Duffield T.F., Leslie K.E., Walton J.S. \& Leblanc S.J. 2012. Risk factors and effects of postpartum anovulation in dairy cows. J. Dairy Sci. 95:1845-1854

Duffield T.F., Lissemore K.D., McBride B.W. \& Leslie K. E. 2009. Impact of hyperketonemia in early lactation dairy cows on health and production. J. Dairy Sci. 92:571-580.

Edmonson A.J., Lean I.J., Weaver L.D., Farver T. \& Webster G. 1989. A body condition scoring chart for Holstein dairy cows. J. Dairy Sci. 72:68-78.

Facó O., Lôbo R.N.B., Martins Filho R. \& Moura A.A.A. 2002. Análise do desempenho produtivo de diversos grupos genéticos Holandês-Gir no Brasil. Revta Bras. Zootec. 31:1944-1952.

Feitosa F.L.F. 2008. Semiologia Veterinária: a arte do diagnóstico. $2^{a}$ ed. Roca, São Paulo. 735p.

Feitosa F.L.F. \& Birgel E.H. 2000. Variação da concentração de imunoglobulinas G e M, de proteína total e suas frações eletroforéticas e da atividade da gamaglutamiltransferase no soro sanguíneo de vacas holandesas, antes e após o parto. Arq. Bras. Med. Vet. Zootec. 52:11-16.

Freitas Júnior J.E., Rocha Júnior V.R., Rennó F.P., Mello M.T.P., Carvalho A.P. \& Caldeira L.A. 2008. Efeito da condição corporal ao parto sobre o desempenho produtivo de vacas mestiças Holandês $\times$ Zebu. Revta Bras. Zootec. 37:116-121.

Friedewald W.T., Levy R.I. \& Fredrickson D.S. 1972. Estimation of the concentration of low-density lipoprotein cholesterol in plasma, without use of the preparative ultracentrifuge. Clin. Chem. 18:499-502.

González F.H.D. 2000. Indicadores sanguíneos do metabolismo mineral em ruminantes, p.31-52. In: González F.H.D., Barcellos J., Patiño H.O. \& Ribeiro L.A. (Eds), Perfil Nutricional em Ruminantes: seu uso em nutrição e doenças nutricionais. Editora da UFRGS, Porto Alegre.

González F.H.D. \& Silva S.C. 2006. Introdução à Bioquímica Clínica Veterinária. $2^{\mathrm{a}}$ ed. Editora da UFRGS, Porto Alegre. 364p.

González F., Muiño R., Pereira V., Campos R. \& Castellote J.L.B. 2009. Indicadores sanguíneos de lipomobilização e função hepática no início da lac- tação em vacas leiteiras de alta produção. Ciênc. Anim. Bras. (Supl.1):6469.

Gueorguieva T.M. \& Gueorguiev I.P. 1997. Serum cholesterol concentration around parturition and in early lactation in dairy cows. Revue Méd. Vét. 148:241-244.

Hammon D.S., Evjen I.M., Dhiman T.R., Goff J.P. \& Walters J.L. 2006. Neutrophil function and energy status in Holstein cows with uterine health disorders. Vet. Immunol. Immunopathol. 113:21-29.

Hocquette J.F. \& Bauchart D. 1999. Intestinal absorption, blood transport and hepatic and muscle metabolism of fatty acids in preruminant and ruminant animals. Reprod. Nutr. Develop. 39:27-48.

Kaneko J.J., Harvey J.W. \& Bruss M.L. 2008. Clinical Biochemistry of Domestic Animals. $6^{\text {th }}$ ed. Academic Press, San Diego. 916p.

Kappel L.C., Ingraham R.H., Morgan E.B., Zeringue L., Wilson D., Babcock D.K. \& Stat M.A. 1984. Relationship between fertility and blood glucose and cholesterol concentrations in Holstein cows. Am. J. Vet. Res. 45:2607-2612.

Köppen W. 1948. Climatologia: con un estúdio de los climas de la Tierra. Fondo de Cultura Economica, Mexico. 478p.

Leblanc S.J., Lissemore K.D., Kelton D.F., Duffield T.F. \& Leslie K.E. 2006. Major advances in disease prevention in dairy cattle. J. Dairy Sc. 89:12671279.

Nath H.C., Baruah K.K., Baruah A., Sarmah H.D. \& Sarmah B.C. 2005. Serum cholesterol and protein in pre, peri and postpartum in cows. Indian Vet. J. 82:519-521.

Oetzel G.R. \& Goof J.P. 2008. Milk fever (parturient paresis) in cows, ewes, and doe goats, p.130-134. In: Andersen D.E. \& Rings M. (Eds), Current Veterinary Therapy Food Animal Practice. $5^{\text {th }}$ ed. W.B. Saunders, St Louis.

Payne J.M., Dew S.M., Manston R. \& Faulks M. 1970. The use of a metabolic profile test in dairy herds. Vet. Rec. 87:150-158.

Pogliani F.C. 2006. Valores de referência e influência dos fatores etários, sexuais e de gestação no lipidograma de bovinos da raça Holandesa, criados no Estado de São Paulo. Dissertação de mestrado em Clínica Veterinária, Faculdade de Medicina Veterinária e Zootecnia, Universidade de São Paulo, São Paulo, SP. 134p. Disponível em <http://www. teses.usp.br/teses/disponiveis/10/10136/tde-31052007-163529/pt-br.php>

Pogliani F.C. \& Birgel Junior E.H. 2007. Valores de referência do lipidograma de bovinos da raça Holandesa, criados no Estado de São Paulo. Braz. J. Vet. Res. Anim. Sci. 44:373-383.

Roberts T., Chapinal N., Leblanc S.J., Kelton D.F., Dubuc J. \& Duffield T.F. 2012. Metabolic parameters in transition cows as indicators for earlylactation culling risk. J. Dairy Sci. 95:3057-3063.

Saut J.P.E. 2008. Influência do puerpério e da retenção de anexos fetais no proteinograma de fêmeas bovinas da raça Holandesa, criadas no Estado de São Paulo. Tese de Doutorado em Clínica Veterinária, Faculdade de Medicina Veterinária e Zootecnia, Universidade de São Paulo, São Paulo, SP. 116p. Disponível em <http://www.teses.usp.br/teses/disponiveis/10/10136/tde-28052008-141522/pt-br.php>

Souza P.M. 1997. Perfil bioquímico sérico de bovinos das raças Gir, Holandesa e Girolanda, criados no Estado de São Paulo: influência de fatores de variabilidade etários e sexuais. Tese de Doutorado em Clínica Veterinária, Faculdade de Medicina Veterinária e Zootecnia, Universidade de São Paulo, São Paulo, SP. 243p.

Souza R.M., Birgel Junior E.H., Ayres M.C.C. \& Birgel E.H. 2004. Influência dos fatores raciais na função hepática de bovinos da Raça Holandesa e Jersey. Braz. J. Vet. Res. Anim. Sci. 41:306-312.

Souza R.M. 2005. Avaliação da função hepática e do lipidograma no período puerperal e pós-puerperal e suas inter-relações com os distúrbios reprodutivos de fêmeas bovinas da raça Holandesa, criadas no Estado de São Paulo. Dissertação de Mestrado em Clínica Veterinária, Faculdade de Medicina Veterinária e Zootecnia, Universidade de São Paulo, São Paulo, SP. 192p. Disponível em <http://www.teses.usp.br/teses/disponiveis/10/10136/tde-19102006-115359/pt-br.php>

Souza R.M., Collona N.A., Garcia R., Birgel D.B. \& Birgel Junior E.H. 2008. Influência do puerpério e da fase pós-puerperal na função hepática de 
vacas da raça Holandesa criadas no Estado de São Paulo. Ciênc. Anim. Bras. 9:140-147.

Souza R.M. \& Birgel Junior E.H. 2009. Influência do puerpério e da fase pós-puerperal no lipidograma de vacas da raça Holandesa criadas no Estado de São Paulo. Braz. J. Vet. Res. Anim. Sci. 46:5-10.

Tainturier D.J., Braun P., Rico A.G. \& Thouvenot J.P. 1984. Variation in blood composition in dairy cows during pregnancy and after calving. Res. Vet. Sci. 37:129-131.

Van den Top A., Van Tol A., Jansen H., Geelen M.J.H. \& Beynen A.C. 2005. Fatty liver in dairy cows postpartum is associated with decreased concentration of plasma triacylglycerols and decreased activity of lipoprotein lipase in adipocytes. J. Dairy Res. 72:129-137.

Vazquez-Añon M., Bertics S., Luck M., Grummer R.R. \& Pinheiro J. 1994.
Peripartum liver triglyceride and plasma metabolites. J. Dairy Sci. 77:1521-1528.

Williams E.J., Fisher D.P., Pfeiffer D.U., England G.C.W., Noakes D.E., Dobson H. \& Sheldon, I.M. 2005. Clinical evaluation of postpartum vaginal mucus reflects uterine bacterial infection and the immune response in cattle. Theriogenology 63:102-117.

Wittwer F. 2000. Marcadores bioquímicos no controle de problemas metabólicos nutricionais em gado de leite, p.53-62. In: González F.H.D., Barcellos J., Patiño H.O. \& Ribeiro L.A. (Eds), Perfil Nutricional em Ruminantes: seu uso em nutrição e doenças nutricionais. Editora da UFRGS, Porto Alegre.

Zambrano W.J. \& Marques Júnior A.P. 2009. Perfil metabólico de vacas mestiças leiteiras do pré-parto ao quinto mês da lactação. Zootec. Tropical 27:475-488. 